\title{
əDDiurnal Black-Sky Surface Albedo Parameterization of Snow
}

\author{
TERHIKKI MANNINEN, EMMIHENNA JÄÄSKELÄINEN, AND AKU RIIHELÄ \\ Finnish Meteorological Institute, Helsinki, Finland
}

(Manuscript received 19 February 2020, in final form 3 July 2020)

\begin{abstract}
Surface albedo, the fraction of incoming solar radiation reflected hemispherically by the surface, is an essential climate variable (ECV) directly related to the energy budget of Earth. The presence and properties of snow cover alter surface albedo significantly, with variability in temporal scales reaching from seasonal to diurnal. The diurnal variation of snow albedo is typically parameterized with the solar zenith angle, but it cannot take into account asymmetry with respect to midday. Using the solar azimuth angle instead is suggested, since especially in the melting season the snow albedo varies highly asymmetrically during the day. To derive a general time- and latitude-independent formula, the azimuth angle values are normalized. Baseline Surface Radiation Network data are used to derive an empirical formula for the diurnal variation of snow black-sky surface albedo. The overall accuracy is on the order of 0.02 , and the relative accuracy is about $3 \%$.
\end{abstract}

\section{Introduction}

The surface albedo of snow is of paramount importance for the global energy budget. When estimating the evolution of surface albedo using satellite data, the problem is that satellite retrievals are instantaneous, and hence some method is needed to estimate the albedo value also at other times of the day. In weather and climate models, the diurnal variation of albedo is parameterized using the solar zenith angle as the dominant parameter (Dickinson et al. 1986; Gardner and Sharp 2010). For snow-free targets, Briegleb and Ramanathan (1982), Briegleb et al. (1986), and Yang et al. (2008) have shown that the diurnal variation of directionalhemispherical reflectance (Schaepman-Strub et al. 2006), also called the black-sky surface albedo (Lucht et al. 2000), is very well described with only the solar zenith angle and the albedo value at a fixed solar zenith angle value. Then the diurnal variation is symmetric with respect to midday. For snow, however, it has been demonstrated that the daily variation of the albedo may be markedly asymmetric (Pirazzini 2004; Wang and Zender 2011).

D Denotes content that is immediately available upon publication as open access.

Corresponding author: Terhikki Manninen, terhikki.manninen@ fmi.fi
For snowpacks with invariant physical properties, the surface albedo will increase with the solar zenith angle because scattering and reflection events produce a higher chance for photons to escape the snow when the solar flux is incident from an oblique angle (Dickinson et al. 1986). Yet the situation is complicated by variation in the snowpack physical properties during the day. Snow grain size (Marshall and Oglesby 1994; Kuipers Munneke et al. 2011) and shape (Kokhanovsky and Zege 2004; Libois et al. 2013; Kokhanovsky and Schreier 2009; Räisänen et al. 2015) are important factors determining snow albedo. Because snow grain size and shape are difficult concepts to unambiguously define and quantify, quantities such as the specific surface area (SSA) are often used to describe the snow grain properties (Legagneux et al. 2002; Gardner and Sharp 2010; Domine et al. 2012).

The layer structure, density, liquid water content, snowpack thickness, surface roughness, and impurities such as black carbon affect the albedo as well (Greuell and Konzelmann 1994, Aoki et al. 2011; Domine et al. 2012; Malik et al. 2014; Thackeray et al. 2015). The close packing of the grains is also reported to affect the albedo (He et al. 2017a). The mixing state of black carbon particles (i.e., either internal or external mixings) is also important (He et al. 2017b; Saito et al. 2019). Snow grain metamorphism during the melting season causes them to grow larger and more rounded, decreasing both SSA 
and albedo. Together with the appearance of meltwater within the snowpack, the surface albedo of a snowpack during the melting season often exhibits a systematic, nearly linear decrease with time during the day. During the night, refreezing increases the albedo again, but not to the level of the previous morning. The difference between the morning and afternoon albedo corresponding to the same solar zenith angle value can easily be as large as 0.25 , when the diurnal variation of the albedo is within the range $0.28-0.58$ (Fig. 1). Shadowing effects of sastrugi and crevasses decrease the snow albedo (Leroux and Fily 1998; Warren et al. 1998; Nolin and Payne 2007; Zhuravleva and Kokhanovsky 2011; Lhermitte et al. 2014). Also, precipitation and surface hoar formation or disappearance will change the albedo value (Picard et al. 2012; Champollion et al. 2013; Gallet et al. 2014).

The diurnal variation of the surface albedo is dominated by the varying incidence angle of incoming solar radiation. Therefore, the surface albedo is usually parameterized with the cosine of the solar zenith angle (Briegleb and Ramanathan 1982; Briegleb et al. 1986; Yang et al. 2008). However, when the surface material properties vary markedly during the day, as in the case of melting snow, the diurnal albedo variation is highly asymmetric with respect to midday. As the cosine of the solar zenith angle value is symmetric versus local midday, it cannot describe this phenomenon. There is a simple analytic relationship between the solar azimuth angle and the solar zenith angle. Hence, the driver of the diurnal variation in a surface albedo parameterization can easily be changed from solar zenith angle to solar azimuth angle. The advantage gained is that the azimuth angle of morning and afternoon differ, so that the asymmetry of the surface albedo diurnal variation can be described with the azimuth angle, without loss of accuracy in the case of materials with noon-symmetric diurnal cycle in surface albedo.

In this study we use Baseline Surface Radiation Network (BSRN; Ohmura et al. 1998; König-Langlo et al. 2013; Driemel et al. 2018) in situ surface albedo data to analyze the diurnal variation of the albedo both in several sites and diverse seasons (section 2). A method to consider the diurnal variation asymmetry is assessed theoretically in section 3a. A general formula for estimating the albedo on the basis of albedo values at fixed zenith angle values is derived in section $3 b$. The accuracy of the derived method is presented in section 4 . Application of the method to satellite reflectance data is demonstrated in section 5. We compare the results with the solar zenith angle-based formula by Yang et al. (2008), which was derived for snow-free surfaces.

\section{Materials}

BSRN (Driemel et al. 2018) curates and provides radiative flux measurement data from a collection of observation sites around the world. The observations of down- and upwelling shortwave radiative flux are based on regularly maintained and calibrated broadband pyranometers. A thorough discussion on the measurement uncertainties of BSRN radiative flux measurements is given in Vuilleumier et al. (2014). Typical measurement uncertainties for the down- and upwelling shortwave (covering $250-3000 \mathrm{~nm}$ ) fluxes are on the order of $2 \%$.

Here, we chose a subset of BSRN sites on the basis of long-term data availability combined with either seasonal or perennial snow presence on-site and the daily minimum solar zenith angle value being at most $60^{\circ}$ (Manninen et al. 2019), as listed in Table 1. Of this selection, Dome C (DOM) is located in Antarctica. Alert (ALE) and Barrow (BAR) are coastal high Arctic sites in the Canadian Archipelago (Nunavut) and Alaska, respectively. Fort Peck (FPE) and Boulder (BOS) are located in the continental United States (Montana and Colorado, respectively). Payerne (PAY) and Tõravere (TOR) are located in Europe (Switzerland and Estonia respectively). ALE, BAR, BOS, PAY, TOR, and FPE are seasonal snow sites, whereas DOM has permanent snow and ice cover. All measurements take place over open ground with no shadowing obstruction effects.

\section{Methods}

\section{a. Empirical formulation of diurnally varying snow albedo}

The solar zenith angle $\theta_{s}$ and the solar azimuth angle $\phi_{s}$ at the local latitude $\Phi$ are related to each other according to (Duffie and Beckman 2013)

$$
\cos \phi_{s}=\frac{\sin \delta-\cos \theta_{s} \sin \Phi}{\sin \theta_{s} \cos \Phi},
$$

where the sun declination $\delta$ depends on the number of days since 0000 UTC 1 January. Yang et al. (2008) describe the diurnal variation of albedo using the solar zenith angle as the varying parameter and the albedo value at $60^{\circ}$ solar zenith angle $\left[\alpha_{\mathrm{dir}}\left(60^{\circ}, \lambda\right)\right]$ as fixed parameter

$$
\alpha_{\text {dir }}\left(\theta_{s}, \lambda\right)=\alpha_{\text {dir }}\left(60^{\circ}, \lambda\right) \frac{1+0.775}{1+1.55 \cos \theta_{s}} .
$$

Here, $\lambda$ denotes the wavelength in question. Combining Eqs. (1) and (2), it is possible to derive the albedo diurnal variation with the solar azimuth angle as the varying parameter. 

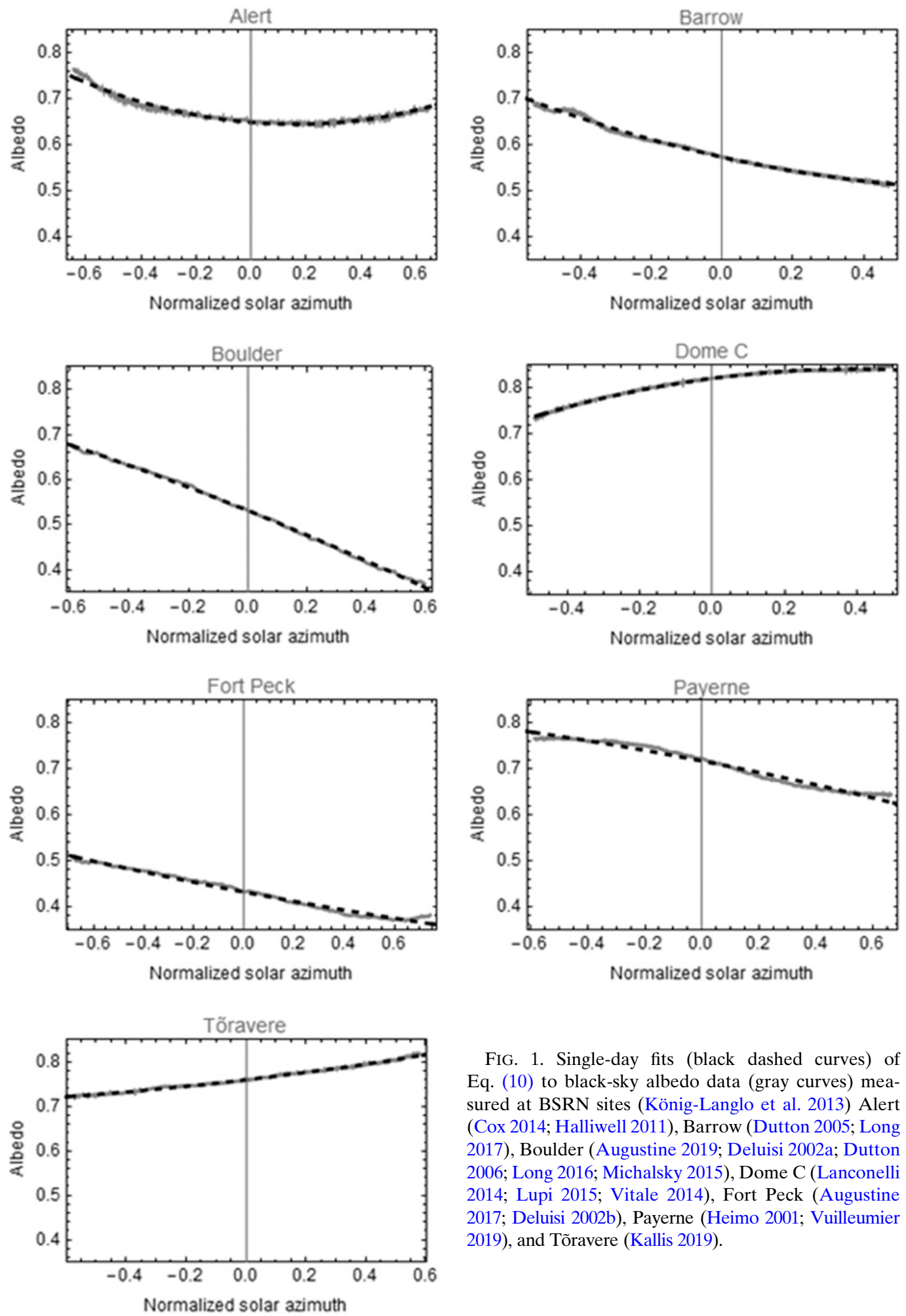

FIG. 1. Single-day fits (black dashed curves) of Eq. (10) to black-sky albedo data (gray curves) measured at BSRN sites (König-Langlo et al. 2013) Alert (Cox 2014; Halliwell 2011), Barrow (Dutton 2005; Long 2017), Boulder (Augustine 2019; Deluisi 2002a; Dutton 2006; Long 2016; Michalsky 2015), Dome C (Lanconelli 2014; Lupi 2015; Vitale 2014), Fort Peck (Augustine 2017; Deluisi 2002b), Payerne (Heimo 2001; Vuilleumier 2019), and Tõravere (Kallis 2019). 
TABLE 1. The BSRN sites used in the study (König-Langlo et al. 2013; Driemel et al. 2018).

\begin{tabular}{lccrr}
\hline \hline In situ site & Event label & Years & Lat & \multicolumn{1}{c}{ Lon } \\
\hline Alert & ALE & $2004-14$ & $82.4900^{\circ} \mathrm{N}$ & $62.4200^{\circ} \mathrm{W}$ \\
Barrow & BAR & $1993-2017$ & $71.3230^{\circ} \mathrm{N}$ & $156.6070^{\circ} \mathrm{W}$ \\
Boulder & BOS & $1995-2019$ & $40.1250^{\circ} \mathrm{N}$ & $105.2370^{\circ} \mathrm{W}$ \\
Dome C & DOM & $2006-15$ & $75.1000^{\circ} \mathrm{S}$ & $123.3830^{\circ} \mathrm{E}$ \\
Fort Peck & FPE & $1995-2017$ & $48.3167^{\circ} \mathrm{N}$ & $105.1000^{\circ} \mathrm{W}$ \\
Payerne & PAY & $1992-2019$ & $46.8150^{\circ} \mathrm{N}$ & $6.9440^{\circ} \mathrm{E}$ \\
Tõravere & TOR & $1999-2019$ & $58.2540^{\circ} \mathrm{N}$ & $26.4620^{\circ} \mathrm{E}$ \\
\hline
\end{tabular}

$$
\alpha\left(\phi_{s}, \delta, \Phi, \lambda\right)=\alpha\left[\phi_{s}\left(\theta_{s}=60^{\circ}\right), \delta, \Phi, \lambda\right] \frac{(1+0.775)}{\left(1+1.55 \frac{\sin \delta \sin \Phi-\cos \phi_{s} \cos \Phi \sqrt{\cos ^{2} \phi_{s} \cos ^{2} \Phi-\sin ^{2} \delta+\sin ^{2} \Phi}}{\cos ^{2} \phi_{s} \cos ^{2} \Phi+\sin ^{2} \Phi}\right)}
$$

The above formula is clumsy, taking into account that it is based on empirical coefficients of Eq. (2). A more attractive approach is to directly derive the albedo diurnal dependence on the solar azimuth angle following the approach presented by Yang et al. (2008). In addition, in order to achieve a more general formula not depending on the latitude or the day of year (declination) we adopt a normalized azimuth angle $\varphi$ varying in the range from -1 to 1 and equaling 0 at midday defined with the following equations:

$$
\begin{aligned}
\varphi & =\frac{\phi_{s}-\phi_{\text {midday }}}{\phi_{\text {sunset }}-\phi_{\text {midday }}}, \\
\phi_{\text {midday }} & =\frac{\phi_{\text {sunrise }}+\phi_{\text {sunset }}}{2}, \quad \text { and } \\
\cos \phi_{\text {sunrise }} & =\cos \phi_{\text {sunset }}=\frac{\sin \delta}{\cos \Phi},
\end{aligned}
$$

where $\phi_{\text {midday }}, \phi_{\text {sunrise }}$, and $\phi_{\text {sunset }}$ denote the local solar azimuth angle values at midday, sunrise, and sunset, respectively. It is considered accurate enough to determine the sunrise and sunset solar azimuth values at the time, when $\theta_{s}$ is equal to $90^{\circ}$ and the midday azimuth angle is taken simply as the average of the azimuth angle values at sunrise and sunset.

Use of the normalized azimuth angle as the parameter enables discriminating mornings and afternoons, so that asymmetric albedo diurnal variation can be described. The complication of using $\varphi$ as the parameter, is that at high latitudes there are periods during which the sun does not rise or set between successive days. There are two alternatives to tackle this problem: either to use $0^{\circ}$ and $360^{\circ}$ solar azimuth angle values for the sunrise and sunset, or to extrapolate the sunrise and sunset values of $\phi_{s}$ outside the variation range of $0^{\circ}-360^{\circ}$. This matter is studied in section $3 \mathrm{~b}$.

Deriving an empirical formula for the snow-covered terrain albedo diurnal variation is reasonable, if the function used is simple. Hence, direct regression of Eq. (3) is not an attractive approach. However, developing Eq. (3) as series with respect to $\cos \phi_{s}$ around zero (i.e., $\phi_{s}=\pi / 2$ ) produces a simple polynomial approximation

$$
\begin{aligned}
\alpha\left(\phi_{s}, \delta, \Phi, \lambda\right)= & \alpha\left[\phi_{s}\left(\theta_{s}=60^{\circ}\right), \delta, \Phi, \lambda\right]\left[\frac{1.775}{1+\frac{1.55 \sin \delta}{\sin \Phi}}+\frac{1.1452 \cos \Phi \sqrt{\sin ^{2} \Phi-\sin ^{2} \delta}}{(\sin \delta+0.6452 \sin \Phi)^{2}} \cos \phi_{s}\right. \\
& \left.+\frac{\cos ^{2} \Phi(0.7388 \sin \delta+1.1452 \sin \Phi)}{(\sin \delta+0.6452 \sin \Phi)^{3}} \cos ^{2} \phi_{s}\right] .
\end{aligned}
$$

On the other hand, the series expansion of $\cos (x)$ and $\cosh (x-\pi)$ around point $x=\pi$ are of the form

$$
-1+\frac{1}{2}(-\pi+x)^{2} \text { and }
$$

$$
1+\frac{1}{2}(-\pi+x)^{2}
$$

respectively. The second-order series expansions differ only by a constant and they are close to the actual value 
of $\cos (x)$ in the range $2 \pi / 3-4 \pi / 3$. Hence, instead of using $\cos \phi_{s}$, the parameterization can be based on $\cosh \phi_{s}$, which is a more natural function to be applied to the normalized solar azimuth angle, which is not in radians. So far, the diurnal variation is still symmetric with respect to midday. Therefore, an additional linear component is allowed to take in to account the effect of snowmelt on the albedo. Thus, the function to be regressed to measurement-based black-sky albedo estimates (section $3 b$ ) is of the form

$$
\alpha(\varphi)=\alpha_{60}\left(\theta_{s}=60^{\circ}, \delta, \Phi\right)\left[c_{0}+c_{1} \varphi+c_{2} \cosh \varphi\right],
$$

where $c_{0}, c_{1}$, and $c_{2}$ denote the linear regression coefficients and $\alpha_{60}$ refers to the albedo value, when the solar zenith angle is equal to $60^{\circ}$. Here $\alpha_{60}$ denotes either the morning $\alpha_{60 \mathrm{~m}}$ or the afternoon $\alpha_{60 \mathrm{a}}$ value or a combination of them. When using both values, it is considered advantageous to allow the slope term to have explicit dependence on their difference as well according to the form

$$
\begin{aligned}
\alpha(\varphi)= & \left(\alpha_{60 \mathrm{~m}}+\alpha_{60 \mathrm{a}}\right)\left\{c_{0}+c_{1}\left[\frac{\left(\alpha_{60 \mathrm{~m}}-\alpha_{60 \mathrm{a}}\right)}{\left(\alpha_{60 \mathrm{~m}}+\alpha_{60 \mathrm{a}}\right)^{2}}\right] \varphi\right. \\
& \left.+c_{2} \cosh \varphi\right\} .
\end{aligned}
$$

\section{b. Data analysis}

For snow, the broadband albedo is dominated by the visible and near-infrared wavelength ranges, where the wavelength dependence of the albedo is modest (Warren and Wiscombe 1980). Hence, it is expected that the diurnal variation of the albedo can reasonably be analyzed using broadband albedo measurements. The black-sky albedo values for the BSRN sites were derived using the approach by Yang et al. (2008), but taking into account the seasonal variation of the white-sky albedo of snow (Manninen et al. 2019). All albedo data available from the seven sites (section 2, Table 1) were first split in daily sets for each site. The lowest albedo value, when the solar zenith angle was smaller than $70^{\circ}$ was allowed to be 0.3 , in order to include the whole melting season of snow in the data. Values for the solar azimuth angle were derived for each day using the latitude and daily declination [Eq. (1)] values. It was considered accurate enough to assume the sunrise and sunset to match the solar zenith angle value $90^{\circ}$. Close to the poles the sun may not rise or set daily. Then one alternative is to use the value $\phi_{s}=0^{\circ}$ for sunrise and $\phi_{s}=360^{\circ}$ for sunset in the Northern Hemisphere and use $\phi_{s}=540^{\circ}$ for sunrise and $\phi_{s}=180^{\circ}$ for sunset in the Southern Hemisphere in order to be able to calculate the normalized azimuth angle values. Another alternative is to extrapolate the linear regression fit of $\phi_{s}$ and $\theta_{s}$ to the value $\theta_{s}=90^{\circ}$ and take the corresponding $\phi_{s}$ values to represent the sunrise and sunset values. These two approaches were tested, and the difference was negligible. Hence, the first (easier) alternative was chosen.

The normalized solar azimuth angle values for the datasets were then calculated using Eq. (4). For each day the linear regression for albedo dependence on the normalized solar azimuth angle was derived using Eq. (10). Then a subset of 10 best days was chosen for each test site to be used for deriving the general regression parameters for Eq. (10). The best days were defined to be the days, when the retrieval of the black-sky albedo value is most reliable. They were selected with a two-step iterative process. First the daily data were sorted separately according to the following criteria in 1) increasing order of the maximum value of the diffuse irradiance, 2) decreasing order of coefficient of determination for the linear regression between the cosine of the solar zenith angle and the global irradiance, 3 ) decreasing order of the coefficient of determination of the linear regression of Eq. (10) of individual days. The cross section of some dozen best days with respect to every three criteria were then taken as input for three other criteria.

These preselected data were then sorted separately in order of 1) decreasing number of measurements, and 2) decreasing order of gaps between individual retrievals, and 3) decreasing order of the difference of the cosine of the daily last and first solar zenith angle values divided by the maximum of the daily cosine of the solar zenith angle value $\left[\Delta \cos \left(\theta_{s}\right) / \max \left(\theta_{s}\right)\right.$ requiring retrievals both before and after midday]. The last criterion was chosen to guarantee that days with dominatingly morning or afternoon data are excluded from the analysis. Larger gaps than $0.25 \mathrm{~h}$ were not allowed and $\Delta \cos \left(\theta_{s}\right) / \max \left(\theta_{s}\right)$ was required be smaller than 0.1 in order to avoid unreliable curve fitting cases. The number of daily retrievals was required to exceed the $10 \%$ daily quantile of the site.

The cross section of the 10 best days of the preselected data being best with respect to the three latter criteria was then taken to be the days to be used for the general regression parameter retrieval (per site). If the cross section of the last step was smaller than 10 days, the process was iterated by taking a larger preselection of the first three criteria. If the cross section of the second set of three criteria produced a larger set than 10 days, a smaller preselection set was taken using the first three criteria. The final 10 days were then obtained iteratively. In Barrow, however, the iteration produced either 9 or 11 days. One of the 11 days was subjectively dropped on the basis that the global radiation curve looked noisier 
than the other curves. For Payerne, only eight snowcovered clear days were originally available and out of them only three passed all required criteria.

First, we studied how well individual linear regression of Eq. (10) fitted to individual daily data for the derived subset of good days. Then, we analyzed whether it is possible to retrieve reliable general parameter values that would apply in all sites. To avoid overfitting to data of only seven sites, the tested alternative regression formulas were kept robust using the following forms:

$$
\begin{aligned}
\alpha(\varphi)= & \alpha_{60 \mathrm{~m}}\left(c_{0}+c_{1} \varphi+c_{2} \cosh \varphi\right), \\
\alpha(\varphi)= & \alpha_{60 a}\left(c_{0}+c_{1} \varphi+c_{2} \cosh \varphi\right), \\
\alpha(\varphi)= & \alpha_{60 \mathrm{a}-1}\left(c_{0}+c_{1} \varphi+c_{2} \cosh \varphi\right), \\
\alpha(\varphi)= & \left(\alpha_{60 \mathrm{~m}}+\alpha_{60 \mathrm{a}}\right)\left[c_{0}+c_{1} \frac{\left(\alpha_{60 \mathrm{~m}}-\alpha_{60 \mathrm{a}}\right)}{\left(\alpha_{60 \mathrm{~m}}+\alpha_{60 \mathrm{a}}\right)^{2}} \varphi\right. \\
& \left.+c_{2} \cosh \varphi\right], \quad \text { and } \\
\alpha(\varphi)= & \left(\alpha_{60 \mathrm{~m}}+\alpha_{60 \mathrm{a}-1}\right)\left[c_{0}+c_{1} \frac{\left(\alpha_{60 \mathrm{~m}}-\alpha_{60 \mathrm{a}-1}\right)}{\left(\alpha_{60 \mathrm{~m}}+\alpha_{60 \mathrm{a}-1}\right)^{2}} \varphi\right. \\
& \left.+c_{2} \cosh \varphi\right] .
\end{aligned}
$$

Taking the reference albedo values $\left(\alpha_{60 \mathrm{~m}}\right.$ and $\left.\alpha_{60 \mathrm{a}}\right)$ as a coefficient to the regression function sets the level of the albedo to the right size. To benefit from known difference of $\alpha_{60 \mathrm{~m}}$ and $\alpha_{60 \mathrm{a}}$ in determination of the linear

term slope an additional coefficient depending on them is added to Eq. (10) to get Eqs. (15) and (16). The derived general parameter values $c_{0}, c_{1}$, and $c_{2}$ and Eq. (10) were then first applied to the data of reference days and finally to $90 \%$ of all days chosen in the order of the same criteria as the 10 best days but not paying attention to the number of measured values per day or to gaps between successive measurements. In addition, the criterion for $\Delta \cos \left(\theta_{s}\right) / \max \left(\theta_{s}\right)$ was relieved to be 0.3 at maximum. The reference days were cloud free, but in the $90 \%$ of days some patchy cloudy days were included (section 4).

The reference solar zenith angle $60^{\circ}$ values were chosen to be the same as used already by Briegleb and Ramanathan (1982), Briegleb et al. (1986), and Yang et al. (2008). Close to poles the solar zenith angle, however, may all the time exceed the reference value. Then the corresponding equations based on a reference albedo value ( $\alpha_{m}$ in the morning, $\alpha_{a}$ in the afternoon and $\alpha_{\mathrm{a}-1}$ in in the previous-day afternoon) of some other fixed solar zenith angle value (corresponding to the normalized azimuth angle value $\varphi_{m}$ in the morning, $\varphi_{a}$ in the afternoon and $\varphi_{\mathrm{a}-1}$ in the previous-day afternoon) are the following (Table 3):

$$
\begin{aligned}
& \alpha(\varphi)=\alpha_{m} \frac{c_{0}+c_{1} \varphi+c_{2} \cosh \varphi}{c_{0}+c_{1} \varphi_{m}+c_{2} \cosh \varphi_{m}}, \\
& \alpha(\varphi)=\alpha_{a} \frac{c_{0}+c_{1} \varphi+c_{2} \cosh \varphi}{c_{0}+c_{1} \varphi_{a}+c_{2} \cosh \varphi_{a}}, \\
& \alpha(\varphi)=\alpha_{a-1} \frac{c_{0}+c_{1} \varphi+c_{2} \cosh \varphi}{c_{0}+c_{1} \varphi_{a-1}+c_{2} \cosh \varphi_{a-1}},
\end{aligned}
$$

$$
\begin{aligned}
\alpha(\varphi)= & {\left[\frac{\alpha_{m} \varphi_{a}+\alpha_{a} \varphi_{m}}{c_{0}\left(\varphi_{a}-\varphi_{m}\right)+c_{2}\left(\varphi_{a} \cosh \varphi_{m}-\varphi_{m} \cosh \varphi_{a}\right)}\right]\left[c_{0}+\frac{c_{0}\left(\alpha_{a}-\alpha_{m}\right)+c_{2}\left(\alpha_{a} \cosh \varphi_{m}-\alpha_{m} \cosh \varphi_{a}\right)}{\alpha_{m} \varphi_{a}-\alpha_{a} \varphi_{m}} \varphi\right.} \\
& \left.+c_{2} \cosh \varphi\right], \text { and } \\
\alpha(\varphi)= & {\left[\frac{\alpha_{m} \varphi_{\mathrm{a}-1}+\alpha_{\mathrm{a}-1} \varphi_{m}}{c_{0}\left(\varphi_{\mathrm{a}-1}-\varphi_{m}\right)+c_{2}\left(\varphi_{a} \cosh \varphi_{m}-\varphi_{m} \cosh \varphi_{\mathrm{a}-1}\right)}\right]\left[c_{0}+\frac{c_{0}\left(\alpha_{\mathrm{a}-1}-\alpha_{m}\right)+c_{2}\left(\alpha_{\mathrm{a}-1} \cosh \varphi_{m}-\alpha_{m} \cosh \varphi_{\mathrm{a}-1}\right)}{\alpha_{m} \varphi_{\mathrm{a}-1}-\alpha_{\mathrm{a}-1} \varphi_{m}} \varphi\right.} \\
& \left.+c_{2} \cosh \varphi\right] .
\end{aligned}
$$

The coefficient $c_{1}$ does not explicitly appear in Eqs. (20) and (21), but it is implicitly there through $\varphi_{m}, \varphi_{a}$, and $\varphi_{a-1}$. To achieve good numerical accuracy, it is recommended to use the solar zenith angle of $60^{\circ}$ as the 
TABLE 2. Statistics for the in situ data of the 10 best days ( 3 best for Payerne) used for deriving a statistical relationship between $\alpha_{\text {black }}$ and $\varphi$ for snow-covered clear days of the BSRN network (König-Langlo et al. 2013; Manninen et al. 2019) for ALE (Cox 2014; Halliwell 2011), BAR (Dutton 2005; Long 2017), BOS (Augustine 2019; Deluisi 2002a; Dutton 2006; Long 2016; Michalsky 2015), DOM (Lanconelli 2014; Lupi 2015; Vitale 2014), FPE (Augustine 2017; Deluisi 2002b), PAY (Heimo 2001; Vuilleumier 2019), and TOR (Kallis 2019). Mean values and standard deviation are given for each site for the number of individual values per day $n$, the maximum value of the fraction of diffuse irradiance during the day diff $\max _{\text {, }}$, the coefficient of determination of the regression of Eq. (10) on daily data $R^{2}(\alpha)$, the coefficient of determination of the linear regression between $\cos \left(\theta_{s}\right)$ and the global irradiance $R^{2}\left(\theta_{s}\right)$, the maximum interval of successive data points gap $_{\max }$, and the difference between the first and last value of $\cos \left(\theta_{s}\right)$ during the day divided by the corresponding daily maximum value $\left[\Delta \cos \left(\theta_{s}\right) / \max \left(\theta_{s}\right)\right]$. The mean and standard deviation of the magnitude of the difference of the estimated and measured albedo values is determined for all points per site together.

\begin{tabular}{|c|c|c|c|c|c|c|c|c|c|c|c|c|c|c|}
\hline \multirow[b]{2}{*}{ In situ site } & \multicolumn{2}{|c|}{$n$} & \multicolumn{2}{|c|}{$\operatorname{diff}_{\max }$} & \multicolumn{2}{|c|}{$R^{2}(\alpha)$} & \multicolumn{2}{|c|}{$R^{2}\left(\theta_{s}\right)$} & \multicolumn{2}{|c|}{$\operatorname{gap}_{\max }(\mathrm{h})$} & \multicolumn{2}{|c|}{$\begin{array}{c}\Delta \cos \left(\theta_{s} /\right. \\
\max \left(\theta_{s}\right)\end{array}$} & \multicolumn{2}{|c|}{$|\hat{a}-\alpha|$} \\
\hline & Mean & Std dev & Max & Mean & Mean & Std dev & Mean & Std dev & Mean & Std dev & Mean & Std dev & Mean & Std dev \\
\hline ALE & 879 & 29 & 0.52 & 0.31 & 0.972 & 0.011 & 0.964 & 0.047 & 0.10 & 0.10 & 0.004 & 0.007 & 0.0027 & 0.0032 \\
\hline BAR & 568 & 52 & 0.88 & 0.82 & 0.957 & 0.030 & 0.997 & 0.002 & 0.08 & 0.08 & 0.037 & 0.060 & 0.0029 & 0.0031 \\
\hline BOS & 164 & 81 & 0.17 & 0.16 & 0.997 & 0.003 & 0.998 & 0.002 & 0.04 & 0.01 & 0.012 & 0.005 & 0.0033 & 0.0030 \\
\hline DOM & 705 & 34 & 0.18 & 0.15 & 0.988 & 0.005 & 0.999 & 0.001 & 0.03 & 0.03 & 0.005 & 0.012 & 0.0021 & 0.0021 \\
\hline FPE & 132 & 35 & 0.75 & 0.36 & 0.863 & 0.094 & 0.970 & 0.048 & 0.12 & 0.08 & 0.059 & 0.059 & 0.0087 & 0.0088 \\
\hline PAY & 334 & 22 & 0.91 & 0.67 & 0.712 & 0.449 & 0.931 & 0.068 & 0.08 & 0.06 & 0.076 & 0.064 & 0.0062 & 0.0078 \\
\hline TOR & 388 & 51 & 0.68 & 0.33 & 0.961 & 0.022 & 0.929 & 0.111 & 0.09 & 0.13 & 0.044 & 0.053 & 0.0023 & 0.0034 \\
\hline
\end{tabular}

reference angle, when it is available in the data used. Only, if the sun is all the time lower than that one should use higher zenith angle values as references.

In places where the albedo is known to have symmetric diurnal variation in midwinter, one can use Eq. (15) assuming that $\alpha_{60 \mathrm{~m}}$ is equal to $\alpha_{60 \mathrm{a}}$. Then the linear term disappears altogether, and the result is precisely symmetric.

\section{Results}

Individual fits of Eq. (10) to the albedo data of good days were in general good (Table 2; Fig. 1), the mean value of $R^{2}(\alpha)$ for all individual fits being 0.92 with a standard deviation of 0.10 . The absolute error of the estimated albedo value $\hat{a}$ was also good, the mean value for the whole dataset being 0.0040 with a standard deviation of 0.0025 , when $\theta_{s} \leq 70^{\circ}$. This supports the hypothesis that using a regression function given by
Eq. (10) is well suited to describe the surface albedo diurnal variation of snow in very different conditions. However, for universal applicability, the goal is to try to find a general formula for the snow albedo diurnal variation in the same style as by Briegleb et al. (1986) and Yang et al. (2008).

Therefore, we tested whether the regression fit is successful when 1) the regression parameters are generalized using the albedo corresponding to the solar zenith angle of $60^{\circ}$ in the morning or in the afternoon, 2) both fixed angle albedo values $\left(\alpha_{60 \mathrm{~m}}\right.$ and $\left.\alpha_{60 \mathrm{a}}\right)$ are used, and 3) when using the previous-day $\alpha_{60 \mathrm{a}}$ value $\left(\alpha_{60 \mathrm{a}-1}\right)$ to provide an estimate for the albedo of the following day, alone or together with $\alpha_{60 \mathrm{~m}}$ of the following day. The results of these tests are shown in Table 3.

The best results were, as expected, obtained using both $\alpha_{60 \mathrm{~m}}$ and $\alpha_{60 \mathrm{a}}$ [Eq. (15)] as reference values. Albedo estimation accuracy was better when using both $\alpha_{60 \mathrm{~m}}$ and $\alpha_{60 \mathrm{a}-1}$ than only $\alpha_{60 \mathrm{~m}}$ or $\alpha_{60 \mathrm{a}}$ as the reference

TABLE 3. General regression parameter values for Eqs. (12)-(16) [and Eqs. (17)-(21)] as based on data of Table 2. The quality of the estimated albedo is characterized by the mean and standard deviation of the absolute difference between the estimated and measured albedo values of all points used for the regression parameter retrieval. The number of points is 29362 when using current-day albedo values as reference and 27393 when using previous-afternoon values as reference. The best fit chosen for further analysis is indicated with boldface font.

\begin{tabular}{|c|c|c|c|c|c|c|}
\hline \multirow[b]{2}{*}{ Eqs. } & \multirow[b]{2}{*}{ Reference albedo } & \multirow[b]{2}{*}{$c_{0}$} & \multirow[b]{2}{*}{$c_{1}$} & \multirow[b]{2}{*}{$c_{2}$} & \multicolumn{2}{|c|}{$|\hat{a}-\alpha|$} \\
\hline & & & & & Mean & $\overline{\text { Std dev }}$ \\
\hline (12) [and (17)] & $\alpha_{60 \mathrm{~m}}$ & 1.0512 & -0.0403 & -0.0519 & 0.031 & 0.036 \\
\hline (13) [and (18)] & $\alpha_{60 \mathrm{a}}$ & 0.8128 & -0.0254 & 0.1810 & 0.029 & 0.039 \\
\hline (14) [and (19)] & $\alpha_{60 \mathrm{a}-1}$ & 0.9101 & -0.0232 & 0.0398 & 0.045 & 0.025 \\
\hline (15) [and (20)] & $\alpha_{60 \mathrm{~m}}$ and $\alpha_{60 \mathrm{a}}$ & 0.4524 & -1.251 & 0.0461 & 0.015 & 0.015 \\
\hline (16) [and (21)] & $\alpha_{60 \mathrm{~m}}$ and $\alpha_{60 \mathrm{a}-1}$ & 0.4559 & 0.0190 & 0.0347 & 0.025 & 0.019 \\
\hline
\end{tabular}


TABLE 4. Quality of albedo estimation applying Eq. (15) (Table 3) to data not used for deriving the regression parameter values. The mean and standard deviation of the absolute and relative differences between the estimated and measured albedo values are given separately for each site and for the total dataset. The number of points and days are given as well. The numbers in parentheses for Barrow and Tõravere exclude points of dubious quality.

\begin{tabular}{|c|c|c|c|c|c|c|}
\hline \multirow[b]{2}{*}{ Site } & \multirow[b]{2}{*}{ Points } & \multirow[b]{2}{*}{ Days } & \multicolumn{2}{|c|}{$|\hat{a}-\alpha|$} & \multicolumn{2}{|c|}{$|\hat{a}-\alpha| / \alpha$} \\
\hline & & & Mean & Std dev & Mean (\%) & Std dev (\%) \\
\hline ALE & 2630 & 3 & 0.007 & 0.010 & 0.9 & 1.2 \\
\hline BAR & 28730 & $61(55)$ & $0.019(0.015)$ & $0.037(0.023)$ & $3.1(2.1)$ & $8.9(6.2)$ \\
\hline BOS & 2011 & 13 & 0.020 & 0.015 & 1.7 & 2.4 \\
\hline DOM & 97981 & 147 & 0.012 & 0.012 & 1.6 & 1.6 \\
\hline FPE & 1111 & 6 & 0.012 & 0.011 & 3.1 & 2.2 \\
\hline TOR & 4277 & $14(13)$ & $0.017(0.014)$ & $0.024(0.017)$ & $2.3(1.8)$ & $4.1(2.1)$ \\
\hline All sites & 137240 & 244 & 0.014 & 0.021 & 1.9 & 4.4 \\
\hline
\end{tabular}

value. When using only one albedo reference value, the afternoon value was better than the morning value.

The mean and standard deviation values for the absolute difference of the estimated and measured albedo values were 0.015 and 0.015 , respectively, for the whole dataset (altogether 29362 point measurements) using the generalized regression parameter values of Eq. (15) (Table 3). The albedo estimation results were equally good for other days than those used for the regression parameter value retrieval (Table 4). The large amount of data from Dome $\mathrm{C}$ dominated the whole dataset, but also the individual sites produced good results. The distributions of the mean deviation of the estimated albedo value from the measured one is shown for all sites in Fig. 2, separately for the best days used for the regression parameter retrieval and the other days. The corresponding distributions for the relative deviation of the estimated albedo value from the measured one are shown in Fig. 3.

The reason for the lower quality of the fit at the Barrow site is that five days dominate the result. Skipping those days, the mean error is at Barrow of the same order as the other sites. For one day, the morning albedo reference value is clearly erroneous due to a data gap. In the four other days, the albedo is very low at midday and it is possible, that those days are actually partly or completely snow free (Fig. 4), the 10\% quantile of the albedo values being smaller than 0.37 . In Tõravere, the poorest fit corresponds to a day of varying illumination conditions and discontinuous measurement (Fig. 5). Removing that day from the statistics produces albedo estimation quality of the same order as in the other sites.

An example of applying Eq. (15) to in situ data from another site than the BSRN sites is shown in Fig. 6, which represents melting-snow season in Sodankylä, Finland $\left(67.368^{\circ} \mathrm{N}, 26.633^{\circ} \mathrm{E}\right)$, on 21 April 1999. The measurement site is in a forested area; hence studying the diurnal variation is possible only up to about solar zenith angle value of $70^{\circ}$, in order to avoid shadowing effects. The black-sky albedo was derived from the measured blue-sky albedo by taking into account the measured fraction of diffuse illumination and the white-sky albedo, which was interpolated from the nearest completely overcast days before and after 21 April, namely, 16 and 29 April. Obviously, the normalized azimuth-based description of the albedo diurnal variation derived in this study is closer to the measured albedo value than the solar zenith angle-based description by Yang et al. (2008) that is not meant for snow-covered areas. The root-mean-square difference between the black-sky albedo values based on measurements and the two estimation methods is 0.013 for Eq. (15) and 0.052 for the method by Yang et al. (2008), when the albedo value varied in the studied range by 0.13 . Obviously, the deviation of Eq. (15) from measurement-based values increases toward the end of the time range used, and it is possible that it is actually caused by an increasing shadowing effect.

\section{Application to satellite data}

Describing the diurnal variation of surface albedo of snow using satellite data is complicated by the fact that

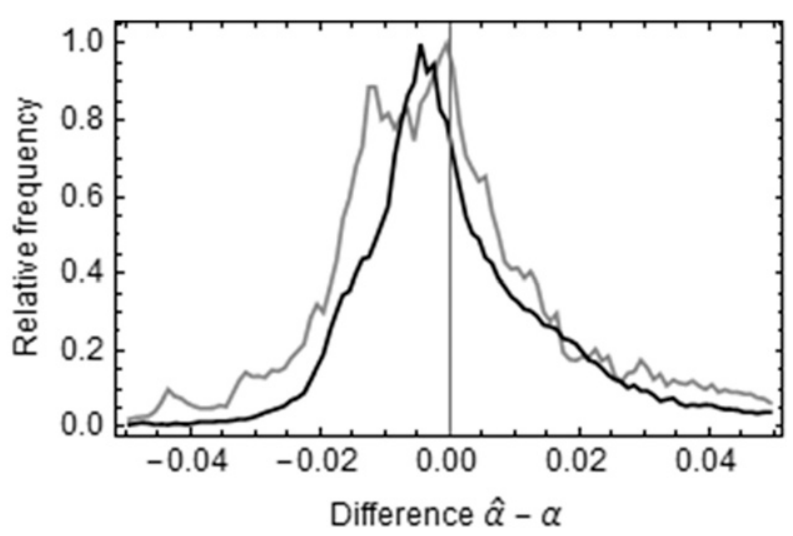

FIG. 2. The distributions of the deviation of the estimated and measured black-sky albedo values for the test sites. The gray curve indicates the fits of the days used for regression parameter retrieval, and the black curve is for the other days. 


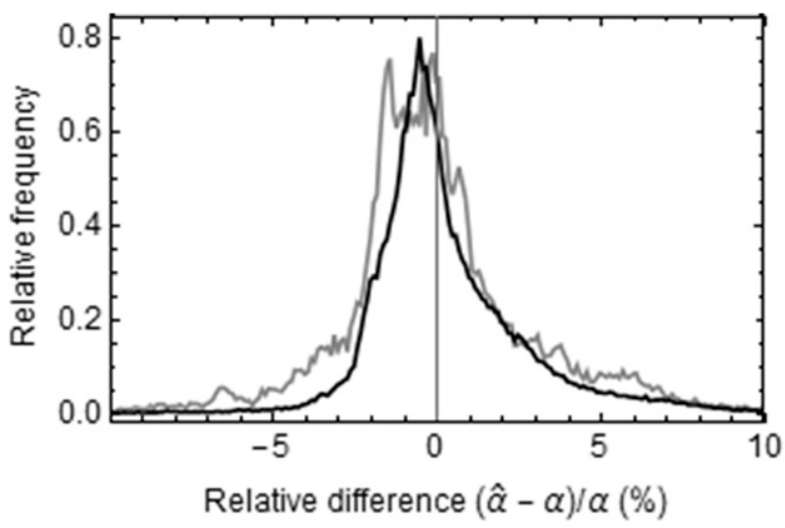

FIG. 3. As in Fig. 2, but for the relative deviation.

the satellite instruments measure the directional reflectance, not the hemispherical albedo. When the bidirectional reflection function is not known, it is not possible to estimate the albedo from a single reflectance value (Wang et al. 2007; Román et al. 2010). The snow albedo of the black-sky surface albedo products Cloud, Albedo and Radiation dataset, AVHRR-based, version 1, surface albedo (CLARA-A1 SAL; Riihelä et al. 2013) and CLARA-A2 SAL (Anttila et al. 2016) rely on sufficient directional representativity of the individual reflectance values within a pixel in one month to justify using the mean broadband reflectance value as an estimate of the albedo. The diurnal variation of the albedo value is then directly related to the diurnal variation of the reflectance value. Examples of the diurnal reflectance variation are shown in Fig. 7 using AVHRR surface reflectance values of MetOp-B, NOAA-15, and NOAA-18 satellites. The cloud probability is limited to $20 \%$ at maximum. The two reference albedo and normalized azimuth angle values were taken to be the average values of the morning and afternoon points. Then Eq. (20) was applied to derive the diurnal variation curve for the albedo.
For the northernmost sea ice area, the daily variation of the solar zenith angle is minimal and also the albedo value is very stable. Then Eq. (20) and the formula by Yang et al. (2008) coincide. For central Greenland, there is no evident melting taking place and the diurnal variation of the albedo is not marked, although the lowest solar zenith angle value is $52.5^{\circ}$. Clearly Eq. (20) matches the data better than the solar zenith angle-based formula (Yang et al. 2008). Melting of snow in Taimyr and Ellesmere Island emphasizes the capability of Eq. (20) to characterize the asymmetric diurnal variation of the snow albedo.

When analyzing satellite reflectance/albedo data, it is essential to pay attention to given quality flags (Schaaf et al. 2011). In addition, one has to remember that then it is mostly a question of scenery albedo (mixed pixels with varying topography and protruding vegetation), more rarely target albedo (homogeneous areas). The heterogeneity typically causes larger variance of the reflectance values, like in the case of Ellesmere Island and Taimyr when compared with the relatively homogeneous central Greenland and Laptev Sea cases (Fig. 7). The vicinity of the sea produces some very low reflectance values to the Ellesmere Island data. Applying the method to larger solar zenith angle values than $70^{\circ}$ degrees is not recommended, as the relationship was derived using data not exceeding that value. In addition, the atmospheric contribution to satellite-based surface reflectance is so dominating for larger solar zenith angle values that one may get very misleading diurnal variation characteristics, when exceeding this limit value (Wang and Zender 2010; Schaaf et al. 2011).

\section{Discussion}

The metamorphosis process taking place during the melting and refreezing modifies the grain size
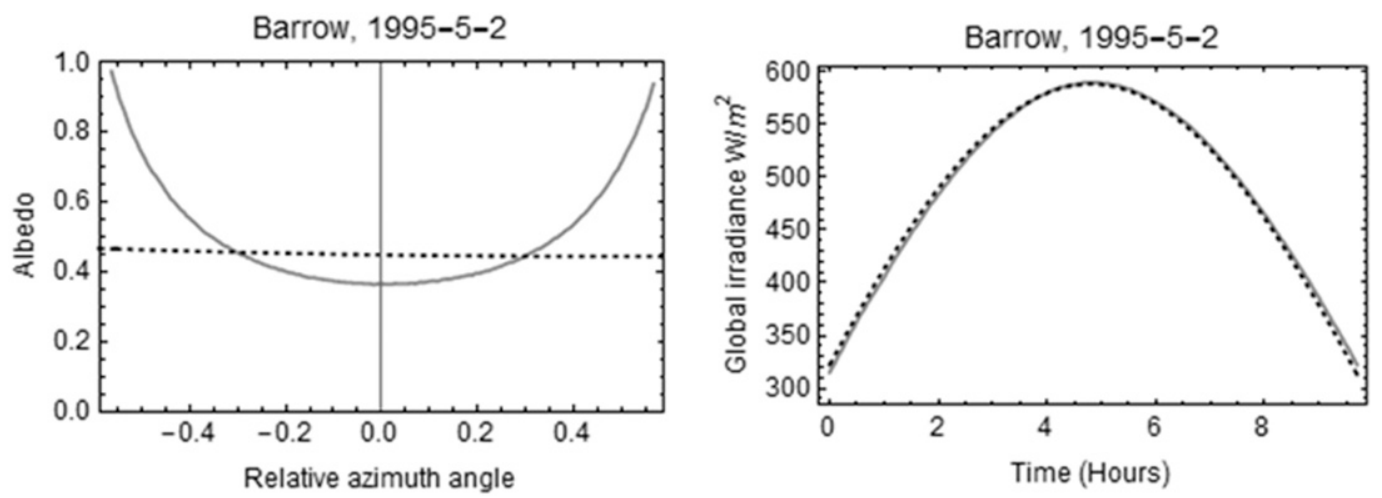

FIG. 4. (left) The measured (gray) and estimated (dotted black) black-sky albedo curves as a function of the normalized azimuth angle in Barrow on 2 May 1995. (right) The measured (gray) and fitted (dotted black) global radiation curves as a function of relative time in Barrow 2 May 1995. 
Töravere, 2009-4-2

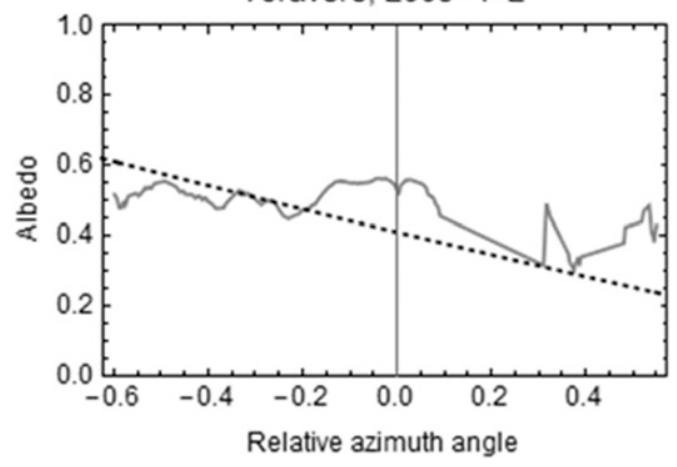

Tõravere, 2009-4-2

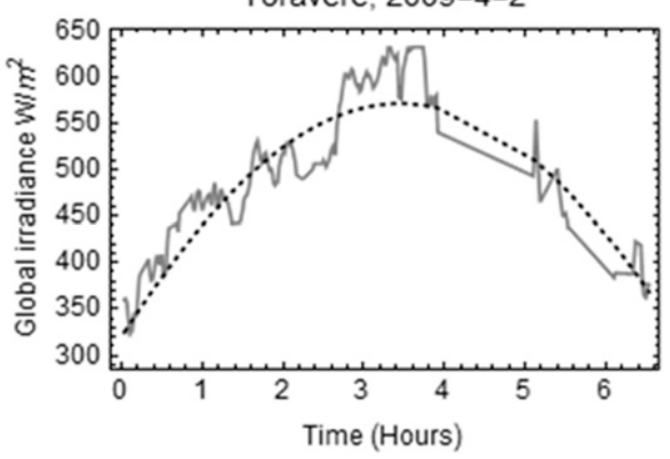

FIG. 5. As in Fig. 4, but for Tõravere on 2 Apr 2009.

continuously, so that the grain size of the snow surface does not typically change radically abruptly. In addition, the process is irreversible: the grains never return to a status they have left (Dirmhirn and Eaton 1975). Therefore, the albedo values of the snow surface during successive days are well correlated. For this reason, forecasting of the diurnal variation of the surface albedo using the albedo values of the morning and afternoon (or previous afternoon) at the solar zenith angle value of $60^{\circ}$ is successful.

However, snowfalls may change the surface albedo more rapidly than the metamorphosis, especially during the melting season, when the grain size of old snow is already large, and the new falling snow is completely different from that. But even then, the rough old snow surface affects to some extent the albedo level and the albedo changes continuously from the prevailing value to that of the new layer (Wang and Zeng 2010; Essery 2015). Also, liquid precipitation during the melting season may cause steep changes in the albedo that may not be well represented by the regression formulas given. Moreover, remote transportation of black carbon or dust may change the albedo quickly, but after the deposition event the snow-cover properties evolve from the new albedo level again continuously (Aoki et al. 2011). In an area dominated by sastrugi or crevasses the diurnal variation of the albedo is sensitive to the azimuth angle difference between the Sun and the dominating direction of these highly anisotropic surface features (Warren et al. 1998; Nolin and Payne 2007). In such areas the diurnal albedo cycle may not be symmetric even without melting, as in Dome C (Fig. 1). Then it is essential to use both morning and afternoon albedo reference values to catch the diurnal albedo variation shape.

The derived formulas can be applied to satellite data to estimate snow albedo values at other times than the satellite overpasses. In addition, in weather and climate models the methods can be used to provide the diurnal

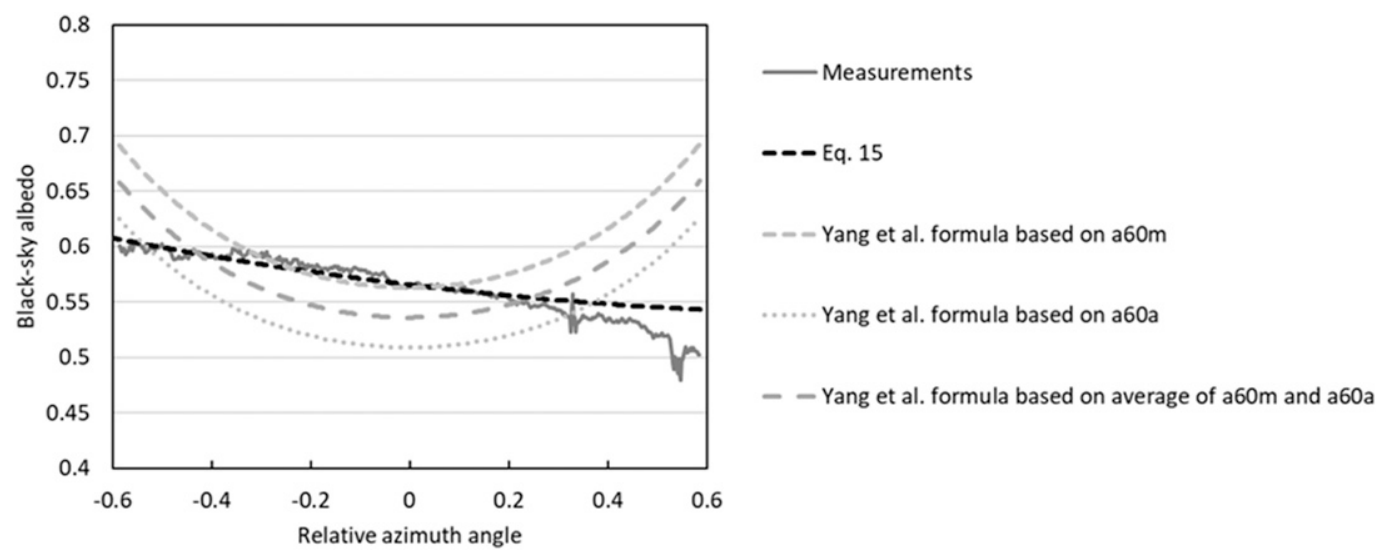

FIG. 6. The black-sky albedo as based on measured blue-sky albedo in Sodankylä 21 Apr 1999 and the corresponding albedo estimated using Eq. (15). The albedo values derived by applying the solar zenith angle-based formula meant for snow-free surfaces by Yang et al. (2008) are shown for comparison, for morning and afternoon reference angles separately. 

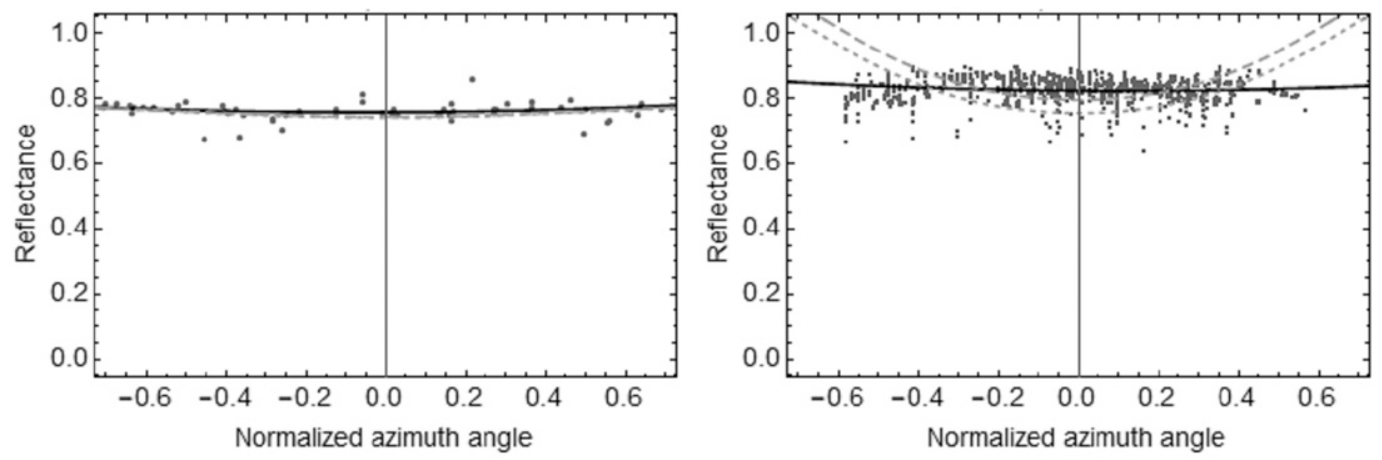

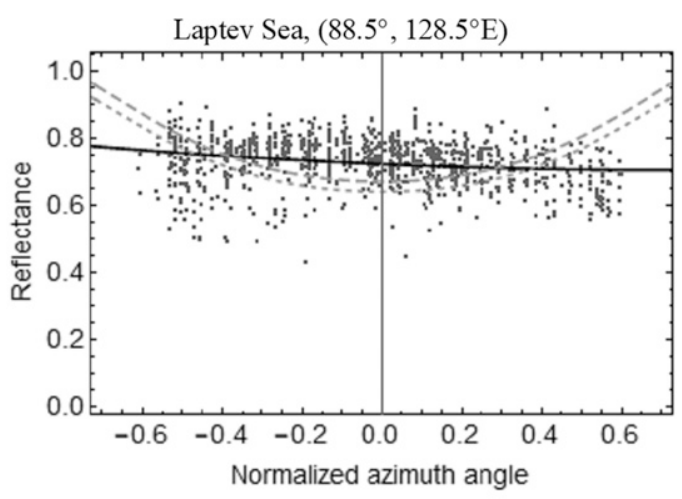

Taimyr, $\left(74.75^{\circ}, 97.25^{\circ} \mathrm{E}\right)$

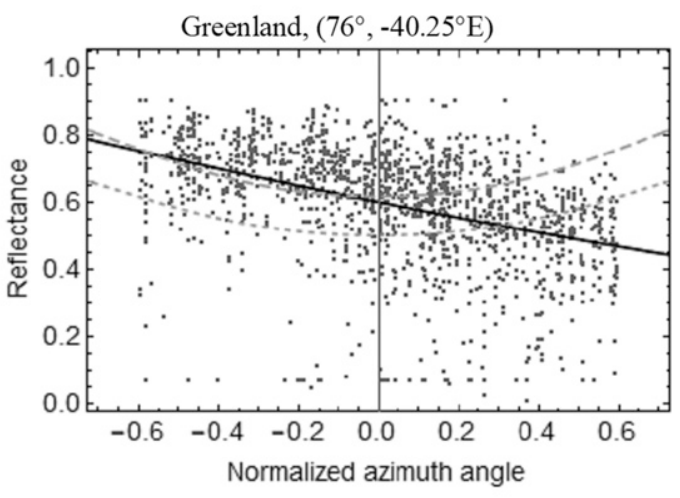

Ellesmere Island, $\left(78.5^{\circ},-75.25^{\circ} \mathrm{E}\right)$

FIG. 7. Diurnal variation of the broadband surface reflectance values derived from AVHRR data of $M e t O p-A$, $N O A A-15$, and $N O A A-18$ at various sites in June 2012 . The pixels are within a $0.25^{\circ}$ from the nominal coordinate in both directions. The black curves show Eq. (20). The curves that are based on the formula by Yang et al. (2008) are shown for comparison for morning (gray dashed) and afternoon (gray dotted).

variation, if the albedo value is modeled for the solar zenith angle of $60^{\circ}$ or some other fixed angle value, but the diurnal variation is not modeled. In general, it is recommended to use Eq. (15), because it provides both the symmetric and asymmetric cases. If only one reference albedo value per day is known, and one knows that the albedo variation is symmetric, then one can assume that the reference values of the morning and afternoon are equal and use Eq. (15), because then the linear term disappears. On the other hand, if it is known that the albedo variation is not symmetric and one has only one reference value per day, then Eq. (12) or (13) is preferred.

\section{Conclusions}

Using empirical data from seven BSRN stations, we derived a general formula to accurately estimate the diurnal variation in black-sky snow albedo. The data contained various kinds of snow data including melting season. The diurnal variation is parameterized with the normalized azimuth angle so that the relationship does not depend explicitly on latitude or time of year, but daily asymmetry is taken into account. When using both morning and afternoon albedo values corresponding to the solar zenith angle of $60^{\circ}$, the overall albedo estimation accuracy varied in the range of $0.1-0.2$ depending on the site. The corresponding relative accuracy varied in the range of $1 \%-3 \%$. If only either morning or afternoon reference albedo value is available, using the afternoon value produces slightly better results with the mean absolute difference being on the order of 0.03. Using as albedo reference values of current-morning and previous-day-afternoon values produced results with accuracy between the two aforementioned cases.

The black-sky snow albedo estimation method presented here is both simple and robust. It is able to account for diurnal variations even when a more refined snow albedo model is not available, when input values for it are missing, or when it is otherwise too computationally intensive.

Acknowledgments. This work was financially supported by Academy of Finland in the project OPTICA (295874) and by EUMETSAT in the project Satellite Application Facility on Climate Monitoring (CM SAF). 
Data availability statement. The BSRN in situ data are available online (https://bsrn.awi.de/). The Sodankylä in situ data are open-access data (https://en.ilmatieteenlaitos.fi/ open-data-manual-accessing-data). The AVHRR data used in the study are stored at ECMWF and are available via the CM SAF project upon request.

\section{REFERENCES}

Anttila, K., E. Jääskeläinen, A. Riihelä, T. Manninen, and K. Andersson, 2016: Algorithm theoretical basis document: CM SAF Cloud, Albedo, Radiation Data Record, AVHRRBased, Edition 2 (CLARA-A2) - surface albedo. EUMETSAT Satellite Application Facility on Climate Monitoring Doc. SAF/CM/FMI/ATBD/GAC/SAL, 85 pp., https://www.cmsaf.eu/ SharedDocs/Literatur/document/2016/saf_cm_fmi_atbd_gac_ sal_2_3_pdf.pdf?_blob=publicationFile.

Aoki, T., K. Kuchiki, M. Niwano, Y. Kodama, M. Hosaka, and T. Tanaka, 2011: Physically based snow albedo model for calculating broadband albedos and the solar heating profile in snowpack for general circulation models. J. Geophys. Res., 116, D11114, https://doi.org/10.1029/2010JD015507.

Augustine, J., 2017: Basic measurements of radiation at station Fort Peck. Subset used: 2002-2017, NOAA/Air Resources Laboratory, Boulder, PANGAEA, accessed 16 September 2019, https://doi.org/10.1594/PANGAEA.900170.

_ 2019: Basic measurements of radiation at station Boulder, SURFRAD. Subset used: 2002-2019, NOAA/Air Resources Laboratory, Boulder, PANGAEA, accessed 16 September 2019, https://doi.org/10.1594/PANGAEA.898857.

Briegleb, B., and V. Ramanathan, 1982: Spectral and diurnal variations in clear sky planetary albedo. J. Appl. Meteor., 21, 1160-1171, https://doi.org/10.1175/1520-0450(1982)021<1160: SADVIC $>2.0$.CO;2.

__, P. Minnis, V. Ramanathan, and E. Harrison, 1986: Comparison of regional clear-sky albedos inferred from satellite observations and model computations. J. Climate Appl. Meteor., 25, 214-226, https://doi.org/10.1175/1520-0450(1986)025<0214: CORCSA $>2.0 . \mathrm{CO} ; 2$.

Champollion, N., G. Picard, L. Arnaud, E. Lefebvre, and M. Fily, 2013: Hoar crystal development and disappearance at Dome C, Antarctica: Observation by near-infrared photography and passive microwave satellite. Cryosphere, 7, 1247-1262, https:// doi.org/10.5194/tc-7-1247-2013.

Cox, C. J., 2014: Basic and other measurements of radiation at station Alert. Subset used: 2012-2014, AeroCan, Wilcox, PANGAEA, accessed 16 September 2019, https://doi.org/ 10.1594/PANGAEA.843225.

Deluisi, J., 2002a: Basic measurements of radiation at station Boulder, SURFRAD. Subset used: 1995-2002, NOAA/Air Resources Laboratory, Boulder, PANGAEA, accessed 16 September 2019, https://doi.org/10.1594/PANGAEA.718572.

_ 2002b: Basic measurements of radiation at station Fort Peck. Subset used: 1995-2002, NOAA/Air Resources Laboratory, Boulder, PANGAEA, accessed 16 September 2019, https:// doi.org/10.1594/PANGAEA.721532.

Dickinson, R. E., A. Henderson-Sellers, P. J. Kennedy, and M. F. Wilson, 1986: Biosphere-Atmosphere Transfer Scheme (BATS) for the Community Climate Model. NCAR Tech. Note NCAR/TN-275+STR, 72 pp., https://doi.org/10.5065/ D6668B58.
Dirmhirn, I., and F. Eaton, 1975: Some characteristics of the albedo of snow. J. Appl. Meteor., 14, 375-379, https://doi.org/10.1175/ 1520-0450(1975)014<0375:SCOTAO $>2.0 . C O ; 2$.

Domine, F., J.-C. Gallet, J. Bock, and S. Morin, 2012: Structure, specific surface area and thermal conductivity of the snowpack around Barrow, Alaska. J. Geophys. Res., 117, D00R14, https://doi.org/10.1029/2011JD016647.

Driemel, A., and Coauthors, 2018: Baseline Surface Radiation Network (BSRN): Structure and data description (19922017). Earth Syst. Sci. Data, 10, 1491-1501, https://doi.org/ 10.5194/essd-10-1491-2018.

Duffie, J. A., and W. A. Beckman, 2013: Solar Engineering of Thermal Processes. 4th ed. John Wiley and Sons, 944 pp.

Dutton, E. G., 2005: Basic measurements of radiation at station Barrow. Subset used: 1993-2005, Climate Monitoring \& Diagnostics Laboratory, Boulder, PANGAEA, accessed 16 September 2019, https://doi.org/10.1594/PANGAEA.668471. , 2006: Basic measurements of radiation at station Boulder. Subset used: 1992-2006, Climate Monitoring \& Diagnostics Laboratory, Boulder, PANGAEA, accessed 16 September 2019, https://doi.org/10.1594/PANGAEA.667898.

Essery, R., 2015: A factorial snowpack model (FSM 1.0). Geosci. Model Dev., 8, 3867-3876, https://doi.org/10.5194/gmd-8-3867-2015.

Gallet, J.-C., F. Domine, J. Savarino, M. Dumont, and E. Brun, 2014: The growth of sublimation crystals and surface hoar on the Antarctic plateau. Cryosphere, 8, 1205-1215, https:// doi.org/10.5194/tc-8-1205-2014.

Gardner, A. S., and M. J. Sharp, 2010: A review of snow and ice albedo and the development of a new physically based broadband albedo parameterization. J. Geophys. Res., 115, F01009, https://doi.org/10.1029/2009JF001444.

Greuell, W., and T. Konzelmann, 1994: Numerical modeling of the energy balance and the englacial temperature of the Greenland Ice Sheet: Calculations for the ETH-Camp Location (west Greenland, $1155 \mathrm{~m}$ a.s.1.). Global Planet. Change, 9, 91-114, https://doi.org/10.1016/0921-8181(94)90010-8.

Halliwell, D., 2011: Basic and other measurements of radiation at station Alert. Subset used: 2004-2011, AeroCan, Wilcox, PANGAEA, accessed 16 September 2019, https://doi.org/ 10.1594/PANGAEA.788635.

He, C., Y. Takano, and K.-N. Liou, 2017a: Close packing effects on clean and dirty snow albedo and associated climatic implications. Geophys. Res. Lett., 44, 3719-3727, https://doi.org/ 10.1002/2017GL072916.

, _ _ K. N. Liou, P. Yang, Q. Li, and F. Chen, 2017b: Impact of snow particle shape and black carbon-snow internal mixing on snow optical properties: Parameterizations for climate models. J. Climate, 30, 10 019-10 036, https://doi.org/10.1175/ JCLI-D-17-0300.1.

Heimo, A., 2001: Basic and other measurements of radiation at station Payerne. Subset used: 1996-2001, Swiss Meteorological Agency, Payerne, PANGAEA, accessed 16 September 2019, https://doi.org/10.1594/PANGAEA.671640.

Kallis, A., 2019: Basic and other measurements of radiation at station Toravere. Subset used: 1999-2019, Tartu Observatoorium, Toravere, Estonia, PANGAEA, accessed 16 September 2019, https://doi.org/10.1594/PANGAEA.897373.

Kokhanovsky, A. A., and E. P. Zege, 2004: Scattering optics of snow. Appl. Opt., 43, 1589-1602, https://doi.org/10.1364/AO.43.001589. , and M. Schreier, 2009: The determination of snow specific surface area, albedo and effective grain size using AATSR space-borne measurements. Int. J. Remote Sens., 30, 919-933, https://doi.org/10.1080/01431160802395250. 
König-Langlo, G., R. Sieger, H. Schmithüsen, A. Bücker, F. Richter, and E. G. Dutton, 2013: The Baseline Surface Radiation Network and its World Radiation Monitoring Centre at the Alfred Wegener Institute. GCOS-174, WCRP Rep. 24/2013, 30 pp., https://bsrn.awi.de/fileadmin/user_upload/bsrn.awi.de/Publications/ gcos-174.pdf.

Kuipers Munneke, P., M. R. van den Broeke, J. T. M. Lenaerts, M. G. Flanner, A. S. Gardner, and W. J. van de Berg, 2011: A new albedo parameterization for use in climate models over the Antarctic ice sheet. J. Geophys. Res., 116, D05114, https:// doi.org/10.1029/2010JD015113.

Lanconelli, C., 2014: Basic and other measurements of radiation at Concordia Station. Subset used: 2006-2014, Institute of Atmospheric Sciences and Climate of the Italian National Research Council, Bologna, PANGAEA, accessed 16 September 2019, https://doi.org/10.1594/PANGAEA.861958.

Legagneux, L., A. Carbanes, and F. Dominé, 2002: Measurement of the specific surface area of 176 snow samples using methane adsorption at 77 K. J. Geophys. Res., 107, 4335, https://doi.org/ 10.1029/2001JD001016.

Leroux, C., and M. Fily, 1998: Modeling the effect of sastrugi on snow reflectance. J. Geophys. Res., 103, 25 779-25 788, https:// doi.org/10.1029/98JE00558.

Lhermitte, S., J. Abermann, and C. Kinnard, 2014: Albedo over rough snow and ice surfaces. Cryosphere, 8, 1069-1086, https:// doi.org/10.5194/tc-8-1069-2014.

Libois, Q., G. Picard, J. France, L. Arnaud, M. Dumont, C. Carmagnola, and M. D. King, 2013: Influence of grain shape on light penetration in snow. Cryosphere, 7, 1803-1818, https:// doi.org/10.5194/tc-7-1803-2013.

Long, C., 2016: Basic and other measurements of radiation at station Boulder. Subset used: 2012-2016, NOAA Earth System Research Laboratory, PANGAEA, accessed 16 September 2019, https://doi.org/10.1594/PANGAEA.858986.

_ 2017: Basic and other measurements of radiation at station Barrow. Subset used: 2002-2017, NOAA Earth System Research Laboratory, PANGAEA, accessed 16 September 2019, https:// doi.org/10.1594/PANGAEA.882450.

Lucht, W., C. B. Schaaf, and A. H. Strahler, 2000: An algorithm for the retrieval of Albedo from space using semiempirical BRDF models. IEEE Trans. Geosci. Remote Sens., 38, 977-998, https://doi.org/10.1109/36.841980.

Lupi, A., 2015: Basic and other measurements of radiation at Concordia Station. Subset used: 2011-2015, Institute of Atmospheric Sciences and Climate of the Italian National Research Council, Bologna, PANGAEA, accessed 16 September 2019, https://doi.org/10.1594/PANGAEA.903092.

Malik, M. J., R. van der Velde, Z. Vekerdy, and Z. Su, 2014: Improving modeled snow albedo estimates during the spring melt season. J. Geophys. Res. Atmos., 119, 7311-7331, https:// doi.org/10.1002/2013JD021344.

Manninen, T., E. Jääskeläinen, and A. Riihelä, 2019: Black and whitesky albedo values of snow: In situ relationships for AVHRRbased estimation using CLARA-A2 SAL. Can. J. Remote Sens., 45, 350-367, https://doi.org/10.1080/07038992.2019.1632177.

Marshall, S., and R. J. Oglesby, 1994: An improved snow hydrology for GCMs. Part 1: Snow cover fraction, albedo, grain size, and age. Climate Dyn., 10, 21-37, https://doi.org/ 10.1007/BF00210334.

Michalsky, J., 2015: Basic measurements of radiation at station Boulder. Subset used: 2010-2015, Climate Monitoring \& Diagnostics Laboratory, Boulder, PANGAEA, accessed 16 September 2019, https://doi.org/10.1594/PANGAEA.820969.
Nolin, A. W., and M. C. Payne, 2007: Classification of glacier zones in western Greenland using albedo and surface roughness from the Multi-angle Imaging SpectroRadiometer (MISR). Remote Sens. Environ., 107, 264-275, https://doi.org/10.1016/ j.rse.2006.11.004.

Ohmura, A., E. G. Dutton, B. Forgan, C. Fröhlich, H. Gilgen, H. Hegner, and R. Philipona, 1998: Baseline Surface Radiation Network (BSRN/WCRP): New precision radiometry for climate research. Bull. Amer. Meteor. Soc., 79, 2115-2136, https://doi.org/10.1175/1520-0477(1998)079<2115: BSRNBW $>2.0 . \mathrm{CO} ; 2$.

Picard, G., F. Domine, G. Krinner, L. Arnaud, and E. Lefebvre, 2012: Inhibition of the positive snow-albedo feedback by precipitation in interior Antarctica. Nat. Climate Change, 2, 795-798, https://doi.org/10.1038/nclimate1590.

Pirazzini, R., 2004: Surface albedo measurements over Antarctic sites in summer. J. Geophys. Res., 109, D20118, https://doi.org/ 10.1029/2004JD004617.

Räisänen, P., A. Kokhanovsky, G. Guyot, O. Jourdan, and T. Nousiainen, 2015: Parameterization of single-scattering properties of snow. Cryosphere, 9, 1277-1301, https://doi.org/ 10.5194/tc-9-1277-2015.

Riihelä, A., T. Manninen, V. Laine, K. Andersson, and F. Kaspar, 2013: CLARA-SAL: A global $28 \mathrm{yr}$ timeseries of Earth's black-sky surface albedo. Atmos. Chem. Phys., 13, 3743-3762, https://doi.org/10.5194/acp-13-3743-2013.

Román, M. O., and Coauthors, 2010: Assessing the coupling between surface albedo derived from MODIS and the fraction of diffuse skylight over spatially-characterized landscapes. Remote Sens. Environ., 114, 738-760, https://doi.org/10.1016/j.rse.2009.11.014.

Saito, M., P. Yang, N. G. Loeb, and S. Kato, 2019: A novel parameterization of snow albedo based on a two-layer snow model with a mixture of grain habits. J. Atmos. Sci., 76, 14191436, https://doi.org/10.1175/JAS-D-18-0308.1.

Schaaf, C. B., Z. Wang, and A. H. Strahler, 2011: Commentary on Wang and Zender-MODIS snow albedo bias at high solar zenith angles relative to theory and to in situ observations in Greenland. Remote Sens. Environ., 115, 1296-1300, https:// doi.org/10.1016/j.rse.2011.01.002.

Schaepman-Strub, G., M. E. Schaepman, T. H. Painter, S. Dangel, and J. V. Martonchik, 2006: Reflectance quantities in optical remote sensing-Definitions and case studies. Remote Sens. Environ., 103, 27-42, https://doi.org/10.1016/j.rse.2006.03.002.

Thackeray, C. W., C. G. Fletcher, and C. Derksen, 2015: Quantifying the skill of CMIP5 models in simulating seasonal albedo and snow cover evolution. J. Geophys. Res. Atmos., 120, 5831-5849, https:// doi.org/10.1002/2015JD023325.

Vitale, V., 2014: Basic measurements of radiation at Concordia Station. Subset used: 2006-2014, Institute of Atmospheric Sciences and Climate of the Italian National Research Council, Bologna, PANGAEA, accessed 16 September 2019, https:// doi.org/10.1594/PANGAEA.736054.

Vuilleumier, L., 2019: Basic and other measurements of radiation at station Payerne. Subset used: 2002-2019, Swiss Meteorological Agency, Payerne, PANGAEA, https://doi.org/10.1594/PANGAEA.901710.

—, M. Hauser, C. Félix, F. Vignola, P. Blanc, A. Kazantzidis, and B. Calpini, 2014: Accuracy of ground surface broadband shortwave radiation monitoring. J. Geophys. Res. Atmos., 119 , 13 838-13 860, https://doi.org/10.1002/2014JD022335.

Wang, X., and C. S. Zender, 2010: MODIS snow albedo bias at high solar zenith angles relative to theory and to in situ observations in Greenland. Remote Sens. Environ., 114, 563-575, https://doi.org/10.1016/j.rse.2009.10.014. 
and —, 2011: Arctic and Antarctic diurnal and seasonal variations of snow albedo from multiyear Baseline Surface Radiation Network measurements. J. Geophys. Res., 116, F03008, https://doi.org/10.1029/2010JF001864.

Wang, Z., and X. Zeng, 2010: Evaluation of snow albedo in land models for weather and climate studies. J. Appl. Meteor. Climatol., 49, 363-380, https://doi.org/10.1175/2009JAMC2134.1. , _ _ and M. Barlage, 2007: Moderate Resolution Imaging Spectroradiometer bidirectional reflectance distribution functionbased albedo parameterization for weather and climate models. J. Geophys. Res., 112, D02103, https://doi.org/ 10.1029/2005JD006736.

Warren, S. G., and W. K. Wiscombe, 1980: A model for the spectral albedo of snow II: Snow containing atmospheric aerosols.
J. Atmos. Sci., 37, 2734-2745, https://doi.org/10.1175/15200469(1980)037<2734:AMFTSA > 2.0.CO;2.

R. E. Brandt, and P. O'Rawe Hinton, 1998: Effect of surface roughness on bi-directional reflectance of Antarctic snow. $J$. Geophys. Res., 103, 25 789-25 807, https://doi.org/10.1029/98JE01898.

Yang, F., K. Mitchell, Y.-T. Hou, Y. Dai, X. Zeng, Z. Wang, and X.-Z. Liang, 2008: Dependence of land surface albedo on solar zenith angle: Observations and model parameterization. J. Appl. Meteor. Climatol., 47, 2963-2982, https://doi.org/ 10.1175/2008JAMC1843.1.

Zhuravleva, T. B., and A. A. Kokhanovsky, 2011: Influence of surface roughness on the reflective properties of snow. J. Quant. Spectrosc. Radiat. Transfer, 112, 1353-1368, https://doi.org/10.1016/j.jqsrt.2011.01.004. 